\title{
Bishop score versus transvaginal ultrasonographic measurement of cervical length in predicting successful labor induction in post-term pregnancy: prospective cohort study
}

\author{
Mansour A. Khalifa ${ }^{1}$, Ahmed M. Abbas ${ }^{1 *}$, Mohammed A. Gaber ${ }^{2}$, Maher Salah ${ }^{1}$
}

\begin{abstract}
${ }^{1}$ Department of Obstetrics and Gynecology, Faculty of Medicine, Assiut University, Assiut, Egypt
${ }^{2}$ Department of Obstetrics and Gynecology, Kom Ombo Central Hospital, Aswan, Egypt
\end{abstract}

Received: 11 September 2018

Accepted: 06 October 2018

\author{
*Correspondence: \\ Dr. Ahmed M. Abbas, \\ E-mail: bmr90@hotmail.com
}

Copyright: () the author(s), publisher and licensee Medip Academy. This is an open-access article distributed under the terms of the Creative Commons Attribution Non-Commercial License, which permits unrestricted non-commercial use, distribution, and reproduction in any medium, provided the original work is properly cited.

\begin{abstract}
Background: The current study aims to compare the efficacy of Bishop score assessment and transvaginal ultrasonographic measurement of the cervical length in prediction of the outcome of labor induction in post-term pregnancy.

Methods: A comparative Prospective observational study conducted in Department of Obstetrics and Gynecology, Kom Ombo central hospital from January 2017 to October 2017. Pregnant women were classified into two groups of Bishop Score Group (1): ladies with (Bishop Score <5) = unfavorable cervix and Group (2): those with (Bishop Score $>5)$ = favorable cervix. Also, they were classified into two groups of cervical lengths: Group (1): women with (cervical length $<25 \mathrm{~mm}$, shorter cervix) and Group (2): those with (cervical length $\geq 25 \mathrm{~mm}$, longer cervix). The Primary outcome was Bishop score by digital examination and Cervical length by TVS.

Results: The study group was 100 women. Regarding sonographic assessment, 44 patients had cervical length $<25$ $\mathrm{mm}$ and the mean cervical length for the whole study group was $25.19 \pm 8.16 \mathrm{~mm}$. Successful induction was achieved in 78 patients $(78 \%)$, while CS was done in 22 patients due to failed induction. No difference between both groups regarding the parity $(\mathrm{p}=0.063)$. When comparing women with successful VD versus those delivered by CS, we found significantly higher Bishop score in the first group $5.12 \pm 1.93$ vs $3.89 \pm 1.71$ in the second group (p=0.002). Additionally, VD group had significantly shorter cervix than CS group (22.31 \pm 7.14 vs. $35.37 \pm 5.80 \mathrm{~mm}, \mathrm{p}=0.007)$. The Bishop score showed significant moderate negative correlation with the cervical length $(\mathrm{r}=-0.589, \mathrm{p}=0.001)$.

Conclusions: Success of labor induction in women undergoing induction due to prolonged pregnancy can be highly predicted by cervical length as it is more objective and accurate than Bishop Score. The $25 \mathrm{~mm}$ cut-off point for cervical length was the best predictor of vaginal delivery.
\end{abstract}

Keywords: Bishop score, Induction of labor, Prolonged pregnancy, Ultrasonography

\section{INTRODUCTION}

Labor is defined as "the process of child birth, beginning with the latent phase of labor, ending with delivery of the placenta." The onset of latent phase is the point at which the mother perceives regular contractions. The latent phase for most ladies ends at between 3 and $4 \mathrm{~cm}$ of cervical dilatation. This threshold may be clinically useful; as it defines cervical dilatation limits beyond which active labor can be expected. ${ }^{1}$ Induction of labor (IOL) is defined as stimulation of uterine contraction before the spontaneous onset of labor for the purpose of accomplishing delivery in ladies with obstetric, medical, or fetal complications of pregnancy. ${ }^{2}$ 
All over the world, labor is induced in approximately $20 \%$ of pregnancies (RCOG, 2011). The commonest indication is prolonged pregnancy and several studies have shown that induction, compared to expectant management, is associated with substantial reduction in perinatal mortality. However, approximately $20 \%$ of women having induction of labor need Cesarean section for delivery. ${ }^{3}$ The incidence of post-term pregnancy is $10 \%$, although this incidence may represent a three-fold or more overestimation because of inaccurate pregnancy dating. ${ }^{4}$ Post-term pregnancy may adversely affect both the mother and the fetus or new born. Prolongation of pregnancy beyond term is accompanied by a significant increase in perinatal morbidity and mortality. ${ }^{5}$ Bishop score has been used to assess the cervix. ${ }^{6}$ A higher score is believed to be associated with reduced labor duration and a higher likelihood of successful induction. ${ }^{7}$ Transvaginal ultrasonographic measurement theoretically, could represent a more accurate assessment of the cervix than digital examination because the supravaginal portion of the cervix usually comprises about $50 \%$ of the cervical length. ${ }^{6}$ This portion is difficult to assess digitally. In addition, effacement is subjective and can vary considerably among examiners. Moreover, effacement is difficult to determine in the closed cervix. In contrast, transvaginal urasonographic cervical measurement is quantitative and easily reproducible. ${ }^{6}$

The aim of this study was to compare the efficacy of transvaginal ultrasonographic measurement of the cervical length and Bishop Score assessment in prediction of outcome of labor induction for postdate pregnancies.

\section{METHODS}

The present study is comparative Prospective observational study in nature conducted at the Department of Obstetrics and Gynecology, Kom Ombo Central Hospital from January 2017 to October 2017.

\section{Inclusion criteria}

- Singleton pregnancy.

- Vertex presentation.

- Gestational age of completed 41 weeks or more, as determined from the date of the last menses and confirmed by sonographic measurements in the first trimester.

- Intact fetal membranes.

- Reassuring fetal heart rate pattern.

- Nulliparous or multiparous (not more than Para 5)

- No contraindication for vaginal delivery.

\section{Exclusion criteria}

- $\quad$ Evidence of cephalo-pelvic disproportion (CPD).

- Grandmultipara (>5).

- Evidence of placenta previa, or any prenatal bleeding.
- Uterine scar.

- Active genital herpes infection.

- Fetal macrosomia: $>4 \mathrm{k} . \mathrm{g}$

- Evidence of IUGR: fundal height is at least $3 \mathrm{~cm}$ below the GA in weeks

- Medical disorders with pregnancy.

All pregnant ladies included in the study were subjected to:

\section{Patient counseling}

They were informed about the goals and methods of the trial and consents were taken.

\section{Full history taking}

Careful and detailed history including: personal, present, family, past, menstrual and obstetric histories.

\section{Examination}

\section{General examination including}

General appearance (weight, height) vital signs (pulse, blood pressure, RR and temperature), examination of head and neck, chest, breast, back, upper and lower limbs.

\section{Abdominal examination including}

Inspection. Palpation; superficial and deep including fundal level, fundal grip, umbilical grip and 1st and 2nd pelvic grips.

\section{Pelvic (local) examination}

\section{Digital examination}

Fulfilling the inclusion criteria, vaginal examination was done only once under aseptic precautions by senior staff for confirmation of presentation and position of the presenting part, exclusion of CPD and to examine the status of the cervix to determine Bishop Score.

- Total Bishop score: 13. A score of $>9$ is taken as imminent labor. Pregnant ladies were classified into two groups of Bishop score.

- Group (1): ladies with (Bishop Score <5) = unfavorable (unripe) cervix.

- Group (2): ladies with (Bishop Score $>5$ ) = favorable (ripe) cervix.

\section{Cervical length measurement by TVS}

\section{Preparation for TVS}

Probe preparation: before insertion, the endovaginal probe was covered with specially fitted sheath, a 
commercially available condom, or the finger of examining glove. The standard ultrasound coupling gel was applied to the probe and care was taken to avoid trapping any air bubble at the tip of the probe where it interfaced with the covering sheath.

A small amount of lubricating gel was applied to the outside of the probe before its insertion into the vagina. The probe was wiped clean with an alcohol wipe after each use.

Patient preparation: The procedure was explained to the lady and her privacy was respected in terms of a bed sheet which was helpful to have a gynecologic examining table that allowed the lady to be put in a dorsal position with flexion of hips and knees. This enabled full insertion of the transvaginal probe. The probe was inserted into either the anterior or the posterior vaginal fornix and was then manipulated to image recognizable structures.

Technique of TVS for assessment of the cervix:

The lady was examined in the dorsal position with flexion of hips and knees with an empty bladder.

- The ultrasound probe was slowly introduced into the vagina and care was taken to avoid exerting over pressure; to avoid artificially lengthen the cervix.

- The probe was gradually advanced with only enough pressure to restore a satisfactory image.

Neither fundal nor suprapubic pressure was applied. A sagittal view of the cervix was obtained where the internal os, the cervical canal and the external os were all visible simultaneously.

- A standardized measurement technique was used.

- Cervical length was measured from the external to the internal cervical os.

- The internal os was described as being closed or open.

- Describe if the amniotic membranes had herniated into the endocervical canal or not.

Pregnant ladies were classified into two groups of cervical lengths:

- Group (1): ladies with (cervical length <25mm, shorter cervix).

- Group (2): ladies with (cervical length $\geq 25 \mathrm{~mm}$, longer cervix).

\section{Induction of labor (IOL)}

\section{During IOL}

Partographs were done and Intrapartum fetal surveillance was done by intermittent auscultation of FHR every
15 mins by sonicaid. IOL was started after the Bishop Score and cervical length by TVS were determined. IOL was done according to Crane et al., 2006, by inserting $25 \mathrm{mcg}$ misoprostol in the form of one vagiprost vaginal tablet deeply in the posterior vaginal fornix. This dose was repeated every $4 \mathrm{hrs}$ when required for a maximum of $100 \mathrm{mcg}$. Before each dose we did vaginal examination to assess cervical score. Once regular uterine contractions were established examination was done on a regular basis hourly; to assess the progress of labor. No further misoprostol was given when 3 uterine contractions /10 mins occurred, each lasting > 40 seconds and inducing changes in the Bishop Score.

The cervix is $>4 \mathrm{~cm}$ dilatation (active phase); augmentation could be started by low dose protocol oxytocin IV drip at least $4 \mathrm{hrs}$ from the last dose of misoprostol. 5 IU oxytocin (syntocinon) was diluted in 500cc Ringer. IV line was used with adequately sized cannula which was started at a site that allowed mobility of the lady's arm. The flow rate used was $10-15 \mathrm{miu} / \mathrm{min}=$ 10-15drops/min.

Maximum total dose of $100 \mathrm{mcg}$ misoprostol was reached. * When the lady became progressing in labor, ARM was done. No further oxytocin was given when the partograph revealed failure of labor to progress, or with a persistent Abnormal FHR trace.

The main outcome parameters of this study:

\section{Primary parameters:}

- Bishop score by digital examination.

- Cervical length by TVS.

2. Secondary parameters:

- Total dose of misoprostol used in IOL.

- Induction to delivery interval.

End points

- Inductions were considered successful if they ended with vaginal delivery within 24 hours from the start of induction with good neonatal outcome.

- Inductions were considered failed if they ended with cesarean section either due to fetal distress or protracted cervix.

- The results of induction success or failure in relation to Bishop score and cervical length, mode of delivery and duration of labor are tabulated and statistically analyzed.

The sample size was calculated using the EPI info 2000 statistical package. The calculation was done using the expected frequencies from previous studies using $95 \%$ confidence interval, $80 \%$ power of the study, the prevalence was $10 \%$ and worst acceptable result $5 \%$. The sample size calculated according to the above criteria was 
97 women. However, 100 women were attempted in this research work to avoid non-response rate. Ethical considerations the proposal was reviewed by the Institutional Review Board (IRB) of Faculty of Medicine Assiut University and approval of Women's Health Hospital was obtained. All data were confidential and not used except for research purposes.

\section{Statistical analysis}

Data entry and data analysis were done using SPSS version 19 (Statistical Package for Social Science). Data were presented as mean and standard deviation. Chisquare and Fisher Exact tests were used to compare between qualitative variables. Independent samples t-test was used to compare between two quantitative variables. Pearson correlation was done to measure correlation between quantitative variables. P-value considered statistically significant when $\mathrm{P}<0.05$.

\section{RESULTS}

The study group was 100 women with age ranging from 20-35 years old, 62 primigravidae and 38 multigravidae. All cases were postdate $>41$ weeks. Fifty-eight patients had bishop score $<5$ before starting induction. The mean bishop score was 5.31 2 2.27. Regarding sonographic assessment, 44 patients had cervical length $<25 \mathrm{~mm}$ and the mean cervical length for the whole study group was $25.19 \pm 8.16 \mathrm{~mm}$. Most of the cases $(68 \%)$ received one tablet of (25mcg misoprostol) to start induction

Successful induction was achieved in 78 patients $(78 \%)$, while CS was done in 22 patients due to failed induction. No difference between both groups regarding the parity $(p=0.063)$. The induction-delivery interval in women with Bishop Score $\geq 5$ was significantly shorter than the induction-delivery interval in those with Bishop Score $<5$ $(11.88 \pm 3.27$ versus $19.64 \pm 4.08$ hours respectively, $\mathrm{p}=0.001$ ). Similarly, the induction-delivery interval in women with cervical length $<25 \mathrm{~mm}$ was significantly shorter than those with cervical length $\geq 25 \mathrm{~mm}$ (10.23 \pm 3.18 vs. $15.46 \pm 3.06$ hours respectively, $p=0.005)$.

When comparing women with successful VD versus those delivered by $\mathrm{CS}$, we found significantly higher Bishop score in the first group $5.12 \pm 1.93$ versus $3.89 \pm 1.71$ in the second group $(\mathrm{p}=0.002)$.

Additionally, VD group had significantly shorter cervix than CS group $(22.31 \pm 7.14$ vs. $35.37 \pm 5.80 \mathrm{~mm}$, $\mathrm{p}=0.007)$. The rate of successful induction was $51.3 \%$ (40/78) from those delivered vaginally in women with Bishop score $<5$ versus $81.8 \%(18 / 22)$ from those delivered by $\mathrm{CS}(\mathrm{p}=0.010)$. The rate of successful induction was $53.8 \%$ (42/78) from those delivered vaginally in women with cervical length $<25$ versus $9.1 \%$ $(2 / 22)$ from those delivered by CS $(\mathrm{p}=0.001)$. The Bishop score showed significant moderate negative correlation with the cervical length $(\mathrm{r}=-0.589, \mathrm{p}=0.001)$ (Figure 1).

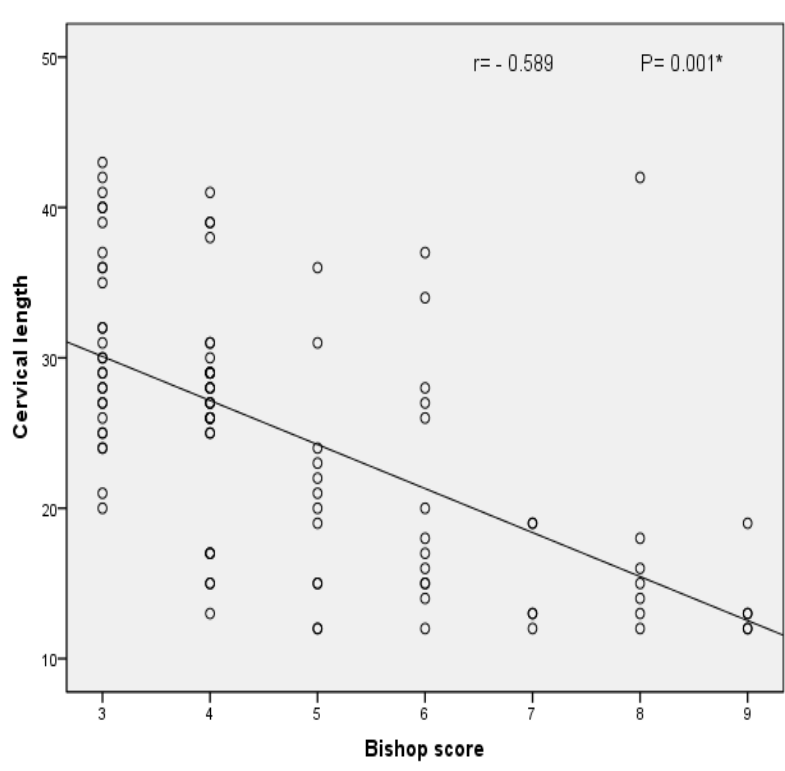

Figure 1: Correlation between Bishop score and cervical length.

\section{DISCUSSION}

Transvaginal ultrasound has gained increasing applications in obstetrics. Its use has primarily focused on detecting cervical change in women at risk for preterm delivery. In this regard, transvaginal ultrasound characteristics, particularly cervical length, have been found to be predictive of impending delivery. ${ }^{8}$ Evaluation of its clinical usefulness in predicting successful labor induction would appear to be a logical progression. One problem with induction of labor is the identification of those patients in whom induction will be mostly successful and those in whom induction will likely fail.

In present study, induction of labor is practiced only for postdate pregnancy; which accounts for about $10 \%$ of pregnancies. For such situation, an accurate method for selecting women who have a high probability of delivering vaginally following induction of labor may have clinical importance.

Currently, the Bishop Score is the most commonly used method for assessing cervical inducibility. This is despite numerous reports of its poor predictive value for the outcome of induction. ${ }^{1}$ Because of that and because the Bishop Score is inherently subjective, it is tempting to believe that an objective method such as transvaginal ultrasonographic assessment of the cervix may be a better predictor for successful induction.

The current study demonstrated that, in 100 singleton pregnancies undergoing induction of labor due to postdate pregnancy utilizing the original Bishop score and transvaginal sonography, the cesarean section rate was $22 \%$ successful vaginal delivery occurred in $78 \%$. The total 100 cases were 38 multiparous cases $(38 \%)$ and 62 nulliparous cases $(62 \%)$. As regard the role of parity 
and gravidity in affecting the mode of delivery. It was found that, the relation was not statistically significant ( $\mathrm{p}$ value (0.241-1.000).

This agrees with Mosbeh and Al Sharkawy, who found that, parity and gravidity were statistically non-significant in the prediction of the success of labor induction and disagrees with Vonda ware et al who found that parity was a main predictor of the mode of delivery. ${ }^{6,9}$ As regard the comparison between Bishop Score and TVS in the prediction of vaginal delivery: Our results showed that the sonographically measured cervical length was better than the Bishop score in predicting the likelihood of vaginal delivery within 24 hour of induction, with sensitivity of $51.28 \%$, specificity of $81.82 \%$ and accuracy of $58 \%$ compared to $46.15 \%, 72.73 \%$ and $52.0 \%$ respectively.

These findings were consistent with those of Pandis et al who found that the cervical length appeared to be a better predictor than the Bishop score, with sensitivity of $87 \%$ and a specificity of $71 \% .{ }^{10}$ The studies which support the superiority of TVS are: Meijer-Hoogeveen et al showed that only the Bishop score correlated significantly with the induction-to-delivery interval in both nulliparous and multiparous ladies; but in nulliparous ladies, only the cervical length measured in the upright position was a significant predictor of the need for CS, with OR 1.14; $95 \%$ CI, 1.02-1.27. ${ }^{11}$

This is different from the present study; may be due to changing the lady's position during TVS; which is a difficult position to be applied. Keepanasseril et al concluded that neither Bishop Score nor its individual parameters were found to be significant in the regression analysis and cervical length and posterior cervical angle by TVS are better than conventional Bishop Score in predicting successful IOL in nulliparous ladies with cutoff point $30 \mathrm{~mm}$ for cervical length with sensitivity of $84.9 \%$, and a specificity of $90.6 \%$, while cut-off point is $100^{\circ}$ for posterior cervical angle with sensitivity $65 \%$ and specificity $72 \% .^{12}$ The differences between such study and the present study may be due to many causes like their use of combination of ultrasonographic parameters which collectively could improve their effect, also the study group was only nulliparous ladies and the posterior cervical angle is not easy to be measured by everyone like the cervical length and it has marked variations with parity. Tan et al., 2007 reported that both cervical length and Bishop Score were useful predictors of CS in IOL with optimal cut-off point of $>20 \mathrm{~mm}$ for the cervical length and $<5$ for the Bishop Score. ${ }^{13}$

Cervical length had superior sensitivity (of $80 \%$ vs. $64 \%$ ) and marginally better PPV (30\% versus $27 \%$ ) and NPV ( $89 \%$ versus $83 \%$ ), but $95 \%$ CI values overlapped. In sub analysis of cases in which CS was performed due to failure to progress, cervical length $>20 \mathrm{~mm}$ remained significantly associated with CS whereas Bishop Score $<5$ was not. The performance of Bishop Score $<5$ and cervical length $>20 \mathrm{~mm}$ as predictors of a prolonged induction-to-delivery interval was very similar.

The differences between such study and the present study may be due to lesser cut-off point for cervical length which is $20 \mathrm{~mm}$ shorter than that in the present study $<25 \mathrm{~mm}$. Other studies which are against the superiority of TVS: Uzun et al reported that Bishop Score, cervical length and posterior cervical angle and funneling were the significant predictors of CS, whereas no such relationship existed for the quantitative echogenicity of the cervical stroma. ${ }^{14}$ Although the difference was not statistically significant, the area under the curve (AUC) was higher for the Bishop Score than that for cervical length and PCA by TVS in the prediction of all CSs.

The best cut-off values to predict CS for Bishop Score, cervical length and posterior cervical angle were $<5$, $>27 \mathrm{~mm}$ and $<98^{\circ}$, respectively. Aragao et al, reported that area under the ROC curve was $0.5(\mathrm{P}=0.8)$ for the TVS measurement of the cervical length, and 0.6 $(\mathrm{P}=0.02)$ for Bishop Score (cut-off point > 4).15 Bishop Score had a sensitivity of $56.2 \%$ and specificity of $67.9 \%$ for prediction of $\mathrm{VD}$, with a positive likelihood ratio of 1.75 and a negative one of 0.65 , so cervical length by TVS was not a good predictor of evolution to VD among ladies with misoprostol induced labor and Bishop Score was a better predictor of VD under these circumstances.

Other studies ended with no difference between Bishop Score and cervical length by TVS: Yanik et al found that Bishop Score, cervical length, maternal age, parity and weight of the newborn all might affect the mode of delivery after IOL. ${ }^{16}$ Bishop score, although a subjective measure must be considered an important component of pre-induction evaluation. This study used combination of many variables and concluded with the importance of Bishop score in preinduction evaluation

Chandra et al compared TVS (cervical length, dilatation, and presence of funneling) with the components of Bishop score. ${ }^{17}$ They found that, TVS does not predict successful IOL or induction to VD interval as well as Bishop Score in postdate pregnancies. Several studies may show that it is a poor predictor of outcome but may help to predict the length of the latent phase. From the above we can see that many parameters can be used for prediction of the mode of delivery after IOL. TVS is the gold standard method of evaluating cervical condition, but we cannot underestimate the value of Bishop score in assessment of the induction of labor so there is a need for conducting comparative studies to evaluate the efficacy of both parameters and thinking about finding a meeting point between the two parameters.

\section{CONCLUSION}

Success of labor induction in women undergoing induction due to prolonged pregnancy can be highly predicted by transvaginal sonography of cervical length 
as it is more objective and accurate than Bishop Score. The $25 \mathrm{~mm}$ cut-off point for cervical length was the best predictor of vaginal delivery.

\section{Recommendations}

Further studies with large sample size and combination of other sonographic parameters as posterior cervical angle and internal os diameter are recommended to verify the efficiency of transvaginal ultrasonography in prediction of successful labor induction.

\section{Funding: No funding sources}

Conflict of interest: None declared

Ethical approval: The study was approved by the Institutional Ethics Committee

\section{REFERENCES}

1. Friedman E, Labor; clinical evaluation and management, $2^{\text {nd }}$ ed New York: Appleton-CenturyCrofts; 1978.

2. Park KH. Transvaginal ultrasonographic cervical measurement in predicting failed labor induction and cesarean delivery for failure to progress in nulliparous women. J Kor Med Sci. 2007;22(4):7227.

3. Crowley P. Interventions for preventing or improving the outcome of delivery at or beyond term. Cochrane Database of Systematic Reviews. 1997(1).

4. Sims ME, Walther FJ. Neonatal morbidity and mortality and long-term outcome of postdate infants. Clinic Obstet, Gynecol. 1989;32(2):285-93.

5. Cunningham FG, MacDonald PC and Gant NF. Post term pregnancy. Williams Obstetrics, $20^{\mathrm{TM}}$ ed. Norwalk, CT: Appleton and Lange; 1997:828.

6. Ware V, Raynor BD. Transvaginal ultrasonographic cervical measurement as a predictor of successful labor induction. Am J Obstet Gynecol. 2000;182(5):1030 -2.

7. Fuentes A, Williams M. Cervical assessment. Clin Obstet Gynecol. 1995; 38(2):224-31.

8. Honest H, Bachmann LM, Coomarasamy A, Gupta JK, Kleijnen J, Khan KS. Accuracy of cervical transvaginal sonography in predicting preterm birth: a systematic review. Ultrasound Obstet Gynecol. 2000;22(3):305-22.

9. Mosbeh MH and Al-Sharkawy EAA: Comparison of the modified Bishop's score, sonographic cervical length and plasma matrix metalloproteinase-9
(MMP-9) in predicting the success of labor induction, Egypt Soc Obstet Gynecol.2001,27:71932.

10. Pandis GK, Papageorghiou AT, Ramanathan VG, Thompson MO, Nicolaides KH. Preinduction sonographic measurement of cervical length in the prediction of successful induction of labor. ultrasound Obstet Gynecol. 2001;18(6):623-28.

11. Meijer-Hoogeveen M, Van Holsbeke C, Van Der Tweel I, Stoutenbeek P, Visser GH. Sonographic longitudinal cervical length measurement in nulliparous women at term: Prediction of spontaneous onset of labor. Ultrasound Obstet Gynecol. 2008;32(5):652- 6.

12. Keepanasseril A, Suri V, Bagga R, Aggarwal N. Preinduction sonographic assessment of the cervix in the prediction of successful induction of labor in nulliparous women. Aust NZJ Obstet Gynaecol.2007;47(5):389-93.

13. Tan PC, Vallikkannu N, Suguna S, Quek KF, Hassan J. Transvaginal sonographic measurement of cervical length vs. Bishop Score in labor induction at term: tolerability and prediction of Cesarean delivery. Ultrasound Obstet Gynecol. 2007;29(5):568-73.

14. Uzun I, Sik A, Şevket O, Aygün M, Karahasanoglu A, Yazicioglu HF. Bishop score versus ultrasound of the cervix before induction of labor for prolonged pregnancy: which one is better for prediction of cesarean delivery. J Maternal-Fetal Neonat Med. 2013;26(14):1450-4.

15. Aragao JB, Fei tosa FE, Alencar Jr, Vasconcelos RP, de Amorim MM, Passini R Jr. Cervical ultrasonography versus Bishop score as a predictor of vaginal delivery. Rev Bras Gynecol Obstet. 2011;33(11):361-6.

16. Yanik A, Gulumser C, Tosun M. Ultrasonographic measurement of cervical length in predicting mode of delivery after oxytocin induction. $\mathrm{Adv}$ Ther.2007;24(4):748-56.

17. Chandra S, Crane JM, Hutchens D, Young DC. Transvaginal ultrasound and digital examination in predicting successful labor induction. American College of Obstet Gynaecol, 2001;98(1):2-6.

Cite this article as: Khalifa MA, Abbas AM, Gaber MA, Salah M. Bishop score versus transvaginal ultrasonographic measurement of cervical length in predicting successful labor induction in post-term pregnancy: prospective cohort study. Int J Reprod Contracept Obstet Gynecol 2018;7:4646-51. 